Rabaska

Revue d'ethnologie de l'Amérique française

\title{
Roger Pinon (1920-2012)
}

\section{Bertrand Bergeron}

Volume 11, 2013

URI : https://id.erudit.org/iderudit/1018528ar

DOI : https://doi.org/10.7202/1018528ar

Aller au sommaire du numéro

Éditeur(s)

Société québécoise d'ethnologie

ISSN

1703-7433 (imprimé)

1916-7350 (numérique)

Découvrir la revue

Citer ce document

Bergeron, B. (2013). Roger Pinon (1920-2012). Rabaska, 11, 176-178.

https://doi.org/10.7202/1018528ar

Ce document est protégé par la loi sur le droit d'auteur. L'utilisation des services d'Érudit (y compris la reproduction) est assujettie à sa politique d'utilisation que vous pouvez consulter en ligne.

https://apropos.erudit.org/fr/usagers/politique-dutilisation/
Cet article est diffusé et préservé par Érudit.

Érudit est un consortium interuniversitaire sans but lucratif composé de l'Université de Montréal, l'Université Laval et l'Université du Québec à Montréal. Il a pour mission la promotion et la valorisation de la recherche. https://www.erudit.org/fr/ 


\section{Nécrologie}

\section{Roger Pinon (1920-2012)}

Avec la disparition de Roger Pinon, la communauté des ethnologues perd un chercheur émérite, estimé et prolifique. Quant à la revue Rabaska, son équipe éditoriale déplore la perte d'un collaborateur éminent et érudit, membre depuis la toute première parution de son comité scientifique.

Résumer une vie qui s'étale sur 92 ans est une tâche impossible à réaliser tant la carrière de Roger Pinon fut fructueuse et éclectique. Au fil des ans, ses intérêts professionnels ont pris une dimension encyclopédique, couvrant des domaines aussi variés que « la

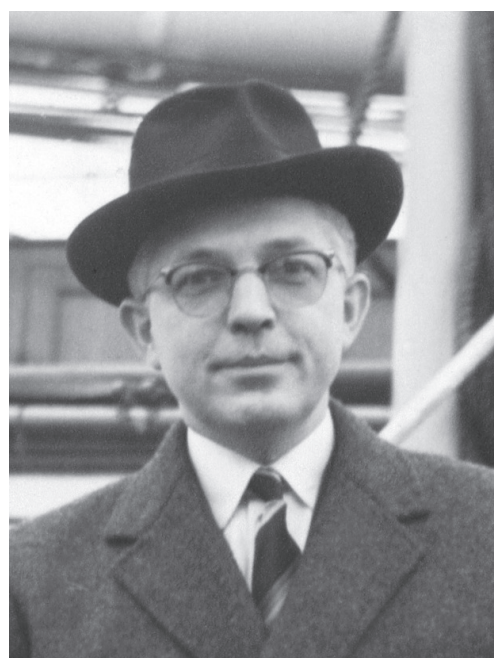
gastronomie populaire, l'enfance et les jeux, l'ethnomusicologie, la faune et la flore, la religion populaire, la vie sociale et les rites calendaires, la dialectologie, [les contes et les légendes, le folklore des métiers, la médecine populaire, la bibliographie ainsi que plusieurs] essais de définition et de conceptualisation de la vie populaire », nous apprend Jean-Pierre Ducastelle dans sa notice nécrologique [«In Memoriam. Roger Pinon (1920-2012)»].

Alain Colignon ${ }^{1}$ mentionne, pour la période s'étendant de 1941 à 2007 , l'existence d'environ « 400 textes de synthèse ou d'érudition » publiés dans sa chère Wallonie ainsi qu'en Italie, en Allemagne, en Argentine et au Québec où il fit un séjour à titre de professeur invité pendant l'année universitaire 1968-1969. Pour expliquer une telle profusion, Roger Pinon n’hésitait pas à se définir comme un chercheur " "besogneux" attaché à établir un "état des lieux" sur un thème donné en y mettant le maximum d'informations vérifiables ».

1. Alain Colignon, « Roger Pinon, l'éclectique du folklore », dans Mélanges en l’honneur de Samuel Glotz, Léon Marquet et Roger Pinon, Bruxelles, Ministère de la communauté française de Belgique, 2007, p. 81-87. À moins d'avis contraire, toutes les citations sont tirées de cet article. 
Il m’a été donné de vérifier personnellement le bien-fondé de cette assertion en procédant à la recension de son livre Les Mille et une mesures du temps. Croissance et décroissance de la journée dans les traditions populaires d'Europe occidentale (Rabaska, vol. 7, 2009) : minutie, souci du détail, exhaustion, concision en étaient les caractéristiques essentielles et révélaient à la fois la méthodologie de l'auteur et son impitoyable discipline intellectuelle. J'ai terminé la lecture de la compilation de ces 1001 dits calendaires avec la profonde conviction que si le chercheur était né au Moyen Âge, il eut volontiers souhaité qu'on l'oubliât dans le scriptorium de quelque monastère dans lequel des moines savants avaient pour vocation de préserver une culture en péril d'oubli.

Pour ceux qui voudraient en connaître plus sur la vie et l'œuvre de Roger Pinon, je ne peux que les référer à l'article d'Alain Colignon cité plus haut. On lui doit également une «Bibliographie sélective » qui donne une idée de l'activité fourmillante de l'éminent chercheur.

Retenons, pour l'essentiel, qu'il est né le 13 avril 1920 à Charleroi où son père, Fernand, avait déménagé pour occuper la fonction de facteur des postes. Très jeune, il se fit remarquer pour sa capacité à maîtriser les langues, ce qui le poussa à s'inscrire à l'Université de Liège « en section de philologie allemande ». Il eut la révélation de sa passion pour la chose folklorique en visitant, à la suggestion d'un ami, le Musée de la vie wallonne.

Ce choc, à la fois émotionnel et intellectuel, l'incita à entreprendre « une recherche comparative entre Flandre et Wallonie sur les jeux d'enfants » qui trouva sa conclusion naturelle dans « une copieuse étude de quelque 377 pages (avec photographies et notations musicales), sous l'intitulé : De Waalsche kinderliteratuur. Een inleiding tot de studie van haar oorsprong, haar traditie en haar expansie in Vlaamsch-België. » Après l'obtention d'un " diplôme de licencié en philologie germanique », débuta une carrière d'enseignant qui occupera une grande partie de sa vie professionnelle : "professeur en langues germaniques à l'athénée de Seraing de 1942 à 1956, puis à l'école normale Jonfosse de 1956 à 1980 ainsi qu'à l'athénée du soir de 1957 à 1980, il ne laissa pas à ses élèves le souvenir d'un magister féroce et morose. »

Parallèlement, il poursuivit une fructueuse carrière d'ethnologue, rencontrant Patrice Coirault, Paul Delarue et Arnold van Gennep dont les savoirs conjugués irriguèrent ses réflexions sur le folklore, ce qui l'amena à délaisser l'approche romantique pour « adopter une démarche davantage socialisante, empreinte de fonctionnalisme et adoptant la notion américaine d'"idées créatrices" et allemande des "élites vers le peuple" [...] ou du "peuple vers les élites" ». Ses nombreuses activités ne l'empêchèrent pas de s'impliquer dans la vie sociale et politique de son pays, se définissant luimême comme un fervent Wallon de gauche. 
En plus de figurer au nombre des membres du comité scientifique de Rabaska, il participa activement à de nombreuses sociétés savantes et collabora à plusieurs revues, notamment au Bulletin des enquêtes.

Un souvenir personnel me relie à sa mémoire. À l'automne 1968, je m'inscrivis à l'Université Laval afin de poursuivre des études en littérature (Études canadiennes, disait-on à l'époque). Parmi la panoplie de cours complémentaires et optionnels, les Archives de folklore en proposaient un portant sur l'ethnographie traditionnelle dont j'ignorais à cette époque jusqu'à l'existence. Je ne puis décider ce qui m'a poussé à m'y inscrire. L'enseignement était donné conjointement par Jean Du Berger, Jean-Claude Dupont et un professeur invité, Roger Pinon. Jean Du Berger brossa un état des lieux de la discipline de manière convaincante et panoramique, Jean-Claude Dupont nous initia aux subtilités de l'enquête sur le terrain. Roger Pinon s'inséra naturellement dans le cours, faisant le pont entre les enseignements de ses deux collègues.

De ma mémoire surgit l'image d'un homme d'âge mûr, de taille moyenne, soigné de sa personne. Son approche pédagogique, tout européenne, tranchait avec le ton et la manière décontractés de ses deux collègues. Elle faisait montre d'une certaine distance et d'une certaine hauteur qui n'étaient pas de la froideur, mais émanaient plutôt de cette assurance issue d'un savoir parfaitement maîtrisé. Roger Pinon exposait les principes fondamentaux de la discipline de manière claire, posée, précise, lumineuse oserais-je ajouter au sens où tout paraissait ancré sur le socle solide de connaissances mille fois avérées. De son enseignement, il m'est resté des concepts opératoires comme les notions élémentaires de culture, d'inculture, de contre-culture, d'acculturation et de déculturation, sans omettre celle de culture hégémonique. La définition scolastique qu'il proposa alors du folklore continue de me ravir par sa virtuosité expressive.

Roger Pinon est passé dans ma vie d'étudiant sans que je ne lui eusse jamais adressé la parole, mais il a marqué ma mémoire de manière indélébile. Dans ce non-temps et ce non-lieu du ciel des ethnologues, je l'imagine qui s'active à débusquer cette mille et deuxième mesure du temps calendaire qui a échappé à son patient ratissage ici-bas. Une année s'est écoulée depuis son décès. Françoise Lempereur lui a succédé à notre comité scientifique ${ }^{2}$. Les rites funéraires, puisque telle est leur fonction, l'ont transformé en ancêtre. Ancêtre inspirant. Référence lumineuse.

Bertrand Bergeron

Saint-Bruno en Lac-Saint-Jean

2. C'est aussi elle qui nous a communiqué la documentation utile à la préparation de cette notice. 